\title{
Towards a Critical Success Factor Framework for Implementing Business Intelligence Systems: A Delphi Study in Engineering Asset Management Organizations
}

\author{
William Yeoh, Jing Gao and Andy Koronios \\ Strategic Information Management Lab, School of Computer and Information Science, \\ University of South Australia, Mawson Lakes, 5095 Australia \\ \{William.Yeoh,Jing.Gao,Andy.Koronios\}@unisa.edu.au
}

\begin{abstract}
This paper presents the results of three rounds Delphi study with 15 BI systems experts in the domain of engineering asset management. The study provides a CSF framework that consists of seven dimensions and 22 factors crucial for successful BI system implementation. The seven critical dimensions of CSFs are management commitment and championship, user-oriented change management, business vision, project planning, team skills and composition, data and infrastructure-related dimensions. These findings allow BI stakeholders to optimize their scarce resources on those key areas that are most likely to have an impact on the implementation of the BI systems.
\end{abstract}

Keywords: Critical success factors, Business analytics, Business intelligence system, Strategic information systems, Delphi method

\section{BACKGROUND}

Engineering asset management organisations (EAMOs), such as utilities and transportation enterprises, store vast amounts of asset-oriented data. However, the data and information environments in these organisations are typically fragmented and characterized by disparate operational, transactional and legacy systems spread across multiple platforms and diverse structures [1]. An ever-increasing amount of such data is often collected for immediate use in assessing the operational health of an asset, and then it is either archived or deleted. This lack of vertical integration of information systems, together with the pools of data spread across the enterprise, makes it extremely difficult for management to make well-informed decisions thus resulting in suboptimal management performance. Moreover, with the many millions of dollars of investment in ERP-style systems, engineering enterprises have been storing large volumes of transactional data, leading to increased difficulties in analyzing, summarizing and extracting reliable information. Meantime, increased regulatory compliance and governance requirements have demanded greater accountability for decision making within such organisations. Bad decisions resulting from poor quality information may have significant financial and reputation implications. In response to these problems, many EAMOs are compelled to improve 
their business execution and management decision support through the implementation of a BI system.

A BI system is primarily composed of a set of three complementary data management technologies, namely data warehousing, online analytical processing (OLAP), and data mining and knowledge discovery [2]. Negash and Gray [3] further posit that "BI systems combine data gathering, data storage, and knowledge management with analytical tools to present complex and competitive information to knowledge workers." Implicit in this definition, the primary objective of BI systems is to improve the timeliness and quality of the input to the decision making process [3]. Data is treated as a corporate resource [4], and transformed from quantity to quality. Hence, actionable information could be delivered at the right time, at the right location, and in the right form [3] to assist individual decision makers, groups, departments, divisions or even larger units [5].

A successful implementation of BI system provides EAMO with a new and unified insight across its entire engineering asset management functions. It drastically reduces the cost of deploying and maintaining a robust environment within one central approach [6]. The resulting unified layer, in reporting, business analysis, and forecasting assures consistency and flexibility. Critical information from many different sources of an asset management enterprise can be integrated into a coherent body for strategic planning and effective allocation of assets and resources. Hence, the various business functions and activities are analyzed collectively to generate more comprehensive information in support of management's decision-making process. BI systems come as standardized software packages from such vendors as Business Objects, Cognos, SAS Institute, Microstrategy, Oracle, Microsoft and Actuate, and they allow customers to adapt them to their specific requirements. Forrester's 2005 survey indicated that for most enterprises BI was the most important application purchase [7]. Furthermore, Merrill Lynch's CIOs spending surveys in February and September of 2005 revealed that BI retained a consistent place in the top three spending priorities [8]. These findings are supported by the 2006 [9] and the February 2007 survey of CIOs conducted by Gartner which similarly found that BI leads the list of the top ten technology priorities [10].

\section{INTRODUCTION AND RESEARCH MOTIVATION}

While BI system implementations bring value to organisations, and though a market may appear vibrant, nevertheless it remains a large and risky financial investment for many organizations. The implementation of a large-scale information system (such as a BI system) is a major event and is likely to cause organisational perturbations [11]. The implementation of a BI system is not a simple activity to purchase a combination of software and hardware; rather it is a complex undertaking and requires a vast amount of resources and infrastructure. Additionally, it includes a variety of stakeholders over a long period, and requires simultaneous attention to a wide variety of technical and non-technical issues [5]. Typical expenditure in these systems includes all BI infrastructure, packaged software, licenses, training, and entire implementation costs, and is always measured in millions of dollars. The 
Towards a Critical Success Factor Framework for Implementing Business Intelligence Systems: A Delphi Study in Engineering Asset Management Organizations

complexity of BI systems is exemplified by Gartner's recent study which revealed that more than half of all implementations experience limited acceptance [12].

Much IS literature suggests that various factors play pivotal roles in the implementation of an information system. However, despite the increasing interest in, and importance of, BI systems, there has been little empirical research about the critical success factors (CSFs) impacting the implementation of BI systems, particularly in EAMOs. Although there is a plethora of BI system studies from the IT industry, nonetheless, most of the existing literature consists of anecdotal reports or quotations based on hearsay. This is because the study of BI systems is a relatively new area that has primarily been driven by the IT industry and vendors [5] and thus there is limited systematic and rigorous research on the CSFs issues of BI system implementation.

On the other hand, there are many studies that investigate the factors that impact the implementation of an information system. While such research is helpful, a BI system is substantially different from a traditional operational or transactional system, a so-called online transactional processing (OLTP) system. OLTP systems are designed to expedite and automate transaction processing, record keeping, and simple reporting of transactions [13]. In other words, the purpose of an OLTP system is to get data into databases of computers. However, a BI system aims to get information out of computer's database [14]. It is an online analytical processing (OLAP) system that is used to support decision-making processes and to facilitate better managerial work. It is also expected to create competitive advantages that make an impact on the bottom line of the organisation [15]. The output information consists of summarized reports and consolidated pictures to facilitate in-sights, new thinking and new understanding of the business to knowledge workers. Hence, a BI system can be viewed as being market-centric with a shrinking information time window as opposed to an operational system that is customer-centric and time specific [16].

What is more, the implementation of a BI system is an infrastructure project, which is defined as a set of shared, tangible IT resources that provide a foundation to enable present and future business applications [17]. Specifically, the key infrastructural component - a data warehouse - is a subject-oriented, integrated, time-variant and non-volatile collection of data that is more demanding than conventional OLTP systems [18]. A complex data structure must be maintained in order to provide an integrated view of the organisation's data so users can query across departmental boundaries for dynamic retrieval of rich decision-support information. Yet this data model throws new challenges as management reporting and analysis become more complex and multidimensional. Furthermore, the implementation of a BI system has to deal with a variety of functional needs, data management, data quality issues, technical issues, and broader enterprise integration and consistency challenges. There is a high degree of complexity in the system's architecture owing to the unstable back-end systems originating from multiple data sources and from the vast volume of data to be processed [19]. These data are used to generate standard reports, and to support the decision making process of knowledge workers as well as ad hoc users. Therefore, the complexities of implementing a BI system and its far reaching business implications justify a more focused examination of the system implementation issues separately from those of traditional information systems. 
There is a need for a CSFs approach to enable BI stakeholders to focus on the key factors that lead to successful BI systems implementation. According to Rockart [20], CSFs are those few critical areas where things must go right for the business to flourish. These limited areas are those in which results, if they are satisfactory, will ensure successful competitive performance for the organisation. If results in these areas are not adequate, then the organisation's effort for the period will be less than desired [20]. As the number of CSFs is limited, senior management is able to constantly focus on the CSFs until they are successfully achieved [21]. Moreover, the relative importance of these CSFs needs to be established, along with in-depth understandings as to why certain factors are perceived to be more critical than others. Also, the identified CSFs need to be classified in ways that suggests meaningful management strategies. Hence, the primary research question under study is: What are the critical success factors and dimensions that influence the implementation of business intelligence systems in EAMOs, and which of these dimensions are most important?

The remainder of this paper has been structured as follows. The next section elaborates on the research methodology for identifying CSFs crucial for implementation of BI systems. The following section then presents the results and the CSFs framework. In this section, the authors also discuss the findings of the study. Then the conclusion and proposals for further research initiatives follows.

\section{RESEARCH METHODOLOGY}

In the absence of much useful literature on BI system, this study seeks to identify a set of CSFs that are jointly agreed by a panel of BI system experts who possess substantial experience in EAMOs. The Delphi method was deemed to be the most appropriate method for this study because it allows the gathering of subjective judgments which are moderated through group consensus [42]. Moreover, this research assumes that expert opinion can be of significant value in situations where knowledge or theory is incomplete, as in the case of BI systems implementation in EAMOs [42]. Also, the method is particularly suitable for this research situation where personal contact between panelists is not desirable because of concerns about the difficulty of ensuring democratic participation.

For this study, a Delphi panel composed of fifteen BI systems experts in EAMOs was established. Ziglio [23] asserts that useful results can be obtained from small group of 10-15 experts. Beyond this number, further increases in understandings are small and not worth the cost or the time spent in additional interviewing [24]. Thus, the size of such a Delphi panel is deemed suitably representative. The panellists have all been substantially involved in the implementation of BI systems within EAMOs in Australia and the United States. They consist of senior representatives of committees of renowned BI associations - such as The Data Warehousing Institute (TDWI) and The Data Warehousing Association of Australia (DWAA), and principal consultants from BI consultancy firms, including two of world's top $100 \mathrm{BI}$ providers. Also, the applied vendors included Cognos, Business Objects, Oracle, Hyperion, Microstrategy, 
Towards a Critical Success Factor Framework for Implementing Business Intelligence

Information Builder, Microsoft, Informatica, SAS Institute, SPF Plus, IBM and Actuate.

In addition, the range of engineering asset management organisations represented by these experts was diverse and included public utilities (such as electricity, gas, water, and waste management) and infrastructure-intensive enterprises such as telecommunications and rail companies. It should be noted that some of the large organisations in which the panellist have been involved have implemented BI projects in a series of phases. Most of the EAMOs are very large companies with engineering assets worth hundreds millions of dollars and have committed immense expenditure to BI projects. So the expertise of the panelists represents 'state of the art' knowledge of BI systems implementation in a broad range of engineering asset-intensive industries.

The Delphi study comprised three rounds. During the first round the authors conducted face-to-face interviews with each panellist (and phone interviews in some cases due to geographical constraints), and these varied in duration from one to oneand-half hours. Rather than having an open-ended question, the authors adopted a different approach from traditional Delphi methods by beginning with a list of factors derived from literature reviews. Having a prior theory has advantages such as allowing the opening and probe questions to be more direct and effective, and helping the researcher recognize when something important has been said [24]. However, the existing literature is not comprehensive in regard to CSFs for an entire BI system, but mainly focuses on data warehousing. Therefore, those factors were mainly used to start each discussion. When the mention of particular factors elicited relevant responses then further probing questions would follow in order to gather more details on those factors. The panelists were indeed encouraged to suggest other factors that they deemed critical. Also, at the commencement of the interviews it was explained that the study focused on CSFs that facilitated the implementation success in terms of infrastructure performance and process performance. The infrastructure performance consists of three major IS success dimensions proposed by Delone and McLean [25, 26], namely system quality, information quality, and system use, whereas process performance is composed of meeting time-schedule and budgetary constraints. After the interview, further clarifications (if any) were made by follow-up phone calls and email communications. Subsequently, the data gathered from the first round of interviews were analyzed thoroughly by content analysis techniques.

In the subsequent round, the suggested factors of all the panelists were consolidated into a singlelist and mapped into their relevant dimensions. The list was then distributed among the participants to facilitate comparison of the panel's perceptual differences. However, none of them nominated any additional factors of their own. In addition, the panel confirmed that the classification of dimensions is appropriate. Also, based on feedback from panel members some further minor changes were incorporated. For instance, several sub-factors are grouped together because of the closed interrelationship. During the third round, the list of candidate CSFs was surveyed by the panel using a structured questionnaire survey approach. Specifically, a 5-point Likert scale was applied to rate the importance of the candidate CSFs in the process of seeking statistical consensus from the BI experts. The purpose of using a 5-point scale from 1 to 5 (where 1 meant 'not important', 2 of 'little 
importance', 3 'important', 4 'very important to 5 'critically important') was to distinguish important factors from critical success factors. From the survey feedback, only those factors with average rating of 3.5 and above were shortlisted as CSFs (as shown in Table 1). These CSFs ratings are considered legitimate because the panelists were directly drawing on their hands-on experience in EAMOs' BI system implementations. The details of the results are discussed below.

\section{RESULTS AND DISCUSSION}

The data collected from Delphi study captured the importance of the seven critical dimensions and associated CSFs within each dimension. The average rating results for the respective dimensions and CSFs are depicted in descending order of importance in table 2. 'Management commitment and championship', 'user-centric change management', and 'business vision dimensions' were viewed as most important by the Delphi panel, followed by 'project planning' and 'team skills and composition'. Surprisingly, data and infrastructure-related issues did not appear to be the most critical dimension relative to the other dimensions. According to most panelists, technological difficulties can be solved by technical solutions. However, it is clear that achieving management and organisational buy-in to support a strategic BI initiative poses the greatest challenge. This organisational commitment is reflected in the attitudes of the various stakeholders; that is, their attitudes to change, time, cost, technology, and project scope, and whether they view data as a valued asset of the organisation.

The research findings further suggest that $\mathrm{BI}$ system implementation is not a oneoff project, but a continual improvement program to leverage decision support. The typical application-based funding for implementation of transactional systems does not apply to BI systems. The BI initiative, especially for the enterprise-wide scale, requires consistent resource allocation and top-management support to overcome organisational issues. These so-called socio-political challenges arise during the course of the cross-functional implementation, as it often uncovers many issues in such areas as business process, data ownership, data quality and stewardship, and organisational structure. Many functional units tend to focus on tactical gains, ignoring the rippling effects imposed on other business units, and one expert observed that, "The people are happy as long as they got their job done... they can't see the overall picture." Moreover, the implementation of BI systems is highly regarded by the panel as a business-driven program as opposed to a technological one. The fulcrum of the success of $\mathrm{BI}$ programs is the business personnel, whereas technical people are expected to achieve the analytical requirements via technologies and tools. Therefore, these new understandings justify the priority of organisational and management dimensions before technological ones. 
Towards a Critical Success Factor Framework for Implementing Business Intelligence Systems: A Delphi Study in Engineering Asset Management Organizations 1359

Table 1. Ratings of Critical Success Factors across Dimensions by Delphi Panel

\begin{tabular}{|c|c|}
\hline Dimensions/Critical Success Factors & Mean \\
\hline Committed management support \& championship & 4.16 \\
\hline - Committed top management support & 4.48 \\
\hline - Adequate resources are provided & 4.14 \\
\hline - A high-level champion from business side & 3.86 \\
\hline User-oriented change management & 4.10 \\
\hline - Formal user involvement throughout the lifecycle & 4.32 \\
\hline - Formal education, training and support are in place & 3.86 \\
\hline Business vision & 4.09 \\
\hline - Well-established business case & 4.14 \\
\hline - Strategic BI vision that is integrated with company initiatives & 4.05 \\
\hline Project planning & 4.08 \\
\hline - Project scope is clearly defined & 4.38 \\
\hline - Adoption of incremental delivery approach & 4.00 \\
\hline - Project scheduled to deliver quick-wins & 3.86 \\
\hline Team skills \& composition & 3.94 \\
\hline - Team possess the right mix of skills & 4.43 \\
\hline - Use of external consultant at early phase & 4.00 \\
\hline - Committed business domain expertise & 3.82 \\
\hline - The team is cross-functional & 3.52 \\
\hline Infrastructure-related issues & 3.90 \\
\hline - Stable source systems are in place & 4.00 \\
\hline - Establishment of a strategic, scalable and extensible technical framework & 3.90 \\
\hline - Prototype is used as proof of concept & 3.80 \\
\hline Data-related issues & 3.82 \\
\hline - High quality of data at source systems & 4.20 \\
\hline - Information area readiness & 3.75 \\
\hline - Business-led establishment of common measures and classifications & 3.80 \\
\hline - Metadata model is sustainable for scalability & 3.65 \\
\hline - Business-led data governance & 3.60 \\
\hline
\end{tabular}




\subsection{Towards a Critical Success Factors Framework}

Based on the findings of this research, these seven dimensions and CSFs were integrated with the implementation success measures to provide a comprehensive CSFs framework for successful implementation of BI systems, particularly in engineering asset management enterprises. Accordingly, the CSFs are mapped into seven dimensions, namely management support and championship, user-oriented change management, business vision, project planning, team skills and composition, data, and infrastructure-related dimensions. Within each dimension there are a number of CSFs which would influence the success of the BI systems implementation. The implementation success of this research takes into account two key dimensions: infrastructure performance, and process performance. The infrastructure performance draws parallels to the three major IS success variables described by Delone and McLean [25, 26], namely system quality, information quality, and system use, whereas process performance can be assessed in terms of time-schedule and budgetary considerations for the relevant phase. Hence, this framework provides a useful guide to BI stakeholders on how to utilize their scarce resources by considering these dimensions and the relevant factors. The discussion of each of the CSFs is as follows.

Of the set of 22 critical success factors, top management commitment has been widely acknowledged as the most important for BI system implementation. Many panelists asserted that consistent support and sponsorship from senior executives make it easier to secure the necessary operating resources such as funding, human skills, organisational support, and other requirements throughout the implementation process. One interviewee pointed out that "if you don't have top level sponsorship - it is doomed!" Another one stated firmly, "no money, no system." This observation is reasonable and expected because the whole BI system implementation effort is a costly, time-consuming, resource-intensive process. Moreover, without dedicated support from top management, the BI project may not receive the proper recognition and hence the support it needs to be successful. This is simply because users tend to conform to the expectations of top management and so are more likely to accept a system backed by their superiors. As pointed out by one participating interviewee, "BI applications take internal time and resources and without an executive communicating the importance and aligning resources the project will not be successful." Also, top management support was deemed critical to solve the organisational resistance and conflicts that may arise during the course of a complex project.

Apart from that, the majority of experts believed that having the right champion from the business side of the organisation is critical for implementation success. 
Towards a Critical Success Factor Framework for Implementing Business Intelligence Systems: A Delphi Study in Engineering Asset Management Organizations 1361

\begin{tabular}{|l|l|}
\hline \multicolumn{1}{|c|}{ Critical Success } \\
Factors
\end{tabular}

Figure 1. A Critical Success Factors Framework for the implementation of Business Intelligence System 
According to them, a business-centric champion would view the BI system primarily in strategic and organisational perspectives, as opposed to one who might over-focus on technical aspects. As noted by a BI consultant, "The team needs a champion. By a champion, I do not mean someone who knows the tools. I mean someone who understands the business and the technology and is able to translate the business requirements into a $\mathrm{BI}$ architecture for the system." Another BI expert commented that "technological issues can sort out later; it is getting users" understanding and showing value to them that are more difficult."

As a BI initiative is driven by business, so a strategic business vision is needed to direct the implementation effort. The panel indicated that a long-term vision, primarily in strategic and organisational terms, is needed to enable an enterprise to progress toward continuous improvement. The strategic vision must be aligned to the business needs, and it must be thoroughly understood because it would eventually impact the adoption and outcome of the BI system. In other words, the implementation of a BI system is an evolutionary process, and its returns should be included in those of the business process as a whole. Furthermore, having a business case is important for sustaining organisational commitment to BI system implementation. Many panelists stressed that a well-established business case that was derived from a detailed analysis of business needs would increase the chances of winning support from top management. As stated by one expert, "A BI system that is not business driven, is a failed system." Thus, a solid business case should incorporate the proposed strategic benefits, resources, risks, costs and the timeline. The panel also highlighted the need for a comprehensive analysis to justify the BI effort, because the system is always measured in millions of dollars, with a high probability of failure. Hence, a solid business case would provide justifiable motivations for adopting a BI system to change the existing reporting and analytical practices.

Having an adequate user-oriented change management effort was deemed critical by the panel. The experts perceive that better user participation in the change effort can lead to better communication of their needs, which in turn can help ensure the system's successful implementation. This is particularly important when the requirements for a system are initially unclear, as is the case with many of the decision-support applications that a BI system is designed to sustain. Significant numbers of panelists explained that user participation can help meet the demands and expectations from various end users, and one panellist asked, "How can the project team design and implement a BI system to meet the users' needs without their involvement?" Hence, the data dimensions, business rules, metadata, and data context that are needed by business users must be considered and incorporated into the system. Another panellist mentioned that “...if the BI project does not involve adequate user participation, then the project is not likely to be successful because the BI application will not satisfy the end users." Moreover, when users are actively involved in the project, they have a better understanding of the potential benefits and this makes them more likely to accept the system on completion.

The Delphi participants also agreed that consistent support for, and systematic training of, end users must not be ignored when aiming for successful BI system implementation. One expert posed the following question, "Will the users of BI system know how to use it? If not, how are they going to make use of the BI application?" Furthermore, panelists emphasized that training should focus on the 
technology itself as well as on the associated management and maintenance issues. This training is important to equip users to understand and experience the features and functions, and to learn about the configured environment and business rules of the BI applications.

The next CSF to be considered is project scoping. According to the panel, adequate project scoping and planning allows the BI team to concentrate on the best opportunity for improvement. To be specific, scoping helps to set clear parameters and develops a common understanding as to what is in scope and what is excluded. As one panelist remarked, "The success of $90 \%$ of our project is determined prior to the first day. This success is based on having a very clear and well-communicated scope, having realistic expectations and timelines, and having the appropriate budget set aside." Moreover, the panel agreed that proper project planning facilitates flexibility and the adaptability to changing requirements within the given timeframe and resources, especially in implementing a complex EAMO-specific BI system. Hence, adequate scoping enables the project team to focus on crucial milestones and pertinent issues while shielding them from becoming trapped in unnecessary events.

In addition, many experts further indicate that it is advisable to start small and adopt an incremental change approach, as large-scale change efforts are always fraught with greater risks given the substantial variables to be managed simultaneously. As noted by one panellist, "Ideally, the sub-project should be scoped as six months or less elapsed time, and preferably with a few releases within that period". Obviously, an incremental delivery approach that starts off on a high-impact area is always valuable to provide tangible evidence for both executive sponsors and key users. Another manager added, "Business organisations are always looking to see immediate impact, and such an incremental delivery approach could provide some results in a short time." In addition, business changes very fast and as such an incremental delivery approach provides the tools for delivery of needed requirements. Undoubtedly, an incremental delivery approach allows an EAMO to concentrate on crucial issues, so enabling teams to prove that the system implementation is feasible and productive for the enterprise.

All interviewees stressed that the composition and skill sets of a BI team have a major influence on the success of the systems implementation. The development team should be composed of those personnel who possess technical expertise and those with a strong business background. As most interviewees noted, a Bl system is a business-driven project to provide enhanced managerial decision support, and so a suitable mix of IT expertise is needed to implement the technical aspects, whereas the reporting and analysis aspects must be under the realm of business personnel. A project manager spoke to this point, simply asserting the need for the "Best of both worlds." Moreover, the panel posits that the BI team must identify and include business domain experts, especially for such activities as data standardization, requirement engineering, data quality analysis, and testing. Many respondents further indicated that external consultants could help to set up project procedures and subsequently oversee quality assurance throughout the entire implementation process. As commented by a panellist, "They bring technology expertise, best practices, and proven project management skills and methodology. External resources are also better at dealing with cultural issues and are not afraid to call out issues." 
Turning now to the data-related dimension, the Delphi findings indicate that the quality of data, particularly at the source systems, is crucial if a BI system is to be implemented successfully. Data quality will affect the quality of management reports, which in turn impact the decision outcomes. Speaking to this point, a BI expert asked, "If the data is corrupt then what is the point?' While another panellist further contended that "If the source systems are unreliable, maybe you shouldn't do a BI project." According to the interviewees, a primary purpose of the BI system is to integrate 'silos' of data sources within EAMOs for further analysis so as to improve the decision-making process. In addition to having the required data collected during the business process, the management of EAMOs are urged to initiate data governance and stewardship efforts to improve the quality of the data in such siloed back-end systems as operational, maintenance, procurement, work management, and inventory control, because unreliable data sources will have a ripple effect on the BI applications and subsequently the decision outcomes.

A BI system provides EAMO users with a dimensional view of data such as engineering assets, and each of the dimensions has its unique measures. In order to have consistent measures and classification across subject areas, the interviewees asserted that business-led commitment is pivotal to establish consensus. The BI team would use those common definitions to develop an enterprise-wide dimensional model that is business orientated. As noted by a panellist, "Not understanding dimensional modelling will cause lots of grief later on and make it difficult to answer some questions." Also, a sustainable metadata model on which to base the logical and physical data warehouse construction for a $\mathrm{BI}$ system plays a key role. The metadata model should be flexible enough to enable the scalability of the BI system while consistently providing integrity on which OLAP and data mining depend.

Another prime concern to the panelists was that the technical framework of a BI system must be able to accommodate scalability and extendibility requirements. Having a strategic view embedded in the system design, this scalable system framework could include additional data sources, attributes, and dimensional areas for fact-based analysis, and it could incorporate external data from suppliers, regulatory bodies, and industrial benchmarks. It would then allow for building a long-term solution as opposed to a short term one. The majority of interviewees agreed that a prototype is always valuable as proof of a concept; that is, constructing a fairly small $\mathrm{BI}$ application for a key area in order to provide tangible evidence for both executive sponsors and general users. They perceive a prototype that offers clear forms of communication, and a better understanding in an important business area would convince organisational stakeholders on the usefulness of a BI system implementation. As a result of a successful prototype, senior management would be more likely and more motivated to support larger-scale BI efforts.

\section{CONCLUDING REMARKS AND FUTURE RESEARCH}

This paper has reported the results of a Delphi study of 15 BI systems experts who have been extensively involved in implementing Bl systems for integrated engineering asset management. An analysis of the findings demonstrated that there 
Towards a Critical Success Factor Framework for Implementing Business Intelligence Systems: A Delphi Study in Engineering Asset Management Organizations 1365

are a number of CSFs peculiar to successful BI system implementation. More importantly, this study revealed a clear trend towards multi-dimensional challenges in implementing BI systems. Non-technical dimensions were perceived to be more important than the technological ones because the BI team considered them to be outside their direct control. The research indicates that the 22 CSFs exist in seven major dimensions, namely management commitment and championship, user-oriented change management, business vision, project planning, team skills and composition, data, and infrastructure-related dimensions. It is also noted that these CSFs do not differ significantly from other non-asset intensive industries. One explanation for this may be that the panel of respondents comprised people experienced in applying industry best practice that is generic in philosophy regardless of the types of industries.

While the specific CSFs may seem to vary slightly between BI systems and general IS studies, the actual contextual and process issues of these CSFs are substantially different from the implementation effort required for conventional operational systems. Unlike those transactional systems, organisational commitment to a BI system implementation is critical to solve the organisational and socio-political issues, especially in the democratization process of data ownership, selection of funding model, change of business process, definition of the scoping study, data stewardship, and quality control, and the provision of domain expertise and championship. Moreover, business functions and key users need to be involved interactively in order to meet their dynamic reporting and ever-changing analytical needs. Owing to the evolutionary information requirements of users, the BI team has to provide continual high-level support not only on tools application, but also at broader data modelling and system scalability issues. This is in line with the adoption of an incremental delivery approach for implementing a sustainable, business-driven BI system. In addition, the data quality initiative - especially at sources - is not a one-off effort but involves active cooperation of frontline workers and consistent governance from respective superiors during the execution of the business process. Furthermore, managing a BI system implementation goes beyond typical IS project management. It requires a massive change in the skills of personnel and in the composition of the team into a cross-discipline and cross-functional one. Indeed, a BI system implementation is a challenging business-oriented infrastructure project involving a spectrum of business, organisational, management, project, team, data and technical issues.

This paper has important implications for research and practice. More specifically, the findings and CSF framework suggest that in investigating the critical factors for BI systems implementation, researchers should not only focus on the technical context but also take into account the factors of organisational, management, team, and project perspectives to provide a more comprehensive research approach. For practitioners, the findings will enable them to better manage their implementation of BI systems if they understand that such implementations involve multiple dimensions of success factors occurring simultaneously and not merely the technical aspects of the system. The participants in this study were highly experienced consultants and so these findings may not be representative of the perceptions of other BI stakeholders, and further research could be conducted into this issue. Therefore, there is a need to 
take into account the CSFs as perceived by the various stakeholders. In the next stage, it is planned to conduct multiple case studies within EAMOs to evaluate the perceptions of practitioners. By comparing the perceptions of these different stakeholders it is expected that a more objective and comprehensive view of the importance of these factors will be obtained.

\section{ACKNOWLEDGMENTS}

This research is conducted through the Cooperative Research Centre for Integrated Engineering Asset Management (CIEAM). The support of CIEAM partners is gratefully acknowledged.

\section{REFERENCES}

1. A. Haider and A. Koronios, Managing Engineering Assets: A Knowledge Based Approach through Information Quality, in Proc. of 2003 International Business Information Management Conference (IBIMA: Cairo, 2003).

2. C.W. Fisher, E. Lauria, I.C. Smith, and R.Y. Wang, Introduction to Information Quality (MITIQ Press: Cambridge, MA, 2006).

3. S. Negash and P. Gray, Business intelligence, in Proc. of Ninth Americas Conference on Information Systems (2003).

4. G.R. Gangadharan and S.N. Swami, Business Intelligence Systems: Design and Implementation Strategies, in Proc of 26th International Conference Information Technology Interfaces ITI (2004).

5. I. Jagielska, P. Darke, and G. Zagari, Business Intelligence Systems for Decision Support: Concepts, Processes and Practice, in Proc. of the 7th International Conference of the International Society for Decision Support Systems (2003).

6. P. Murthy and K. Rao, Business Intelligence and Its Value, in 5th Annual Forbes Global CEO Conference (Sydney, 2005).

7. J. Wirth, Top 10 Trends in Business Intelligence. http://www.b-eyenetwork.com/view/2717? jsessionid=8417aae931842 (Accessed May 11 2006)

8. CIO, Business Intelligence. http://www.cio.com/specialreports/business_intelligence.html (Accessed April 11 2006).

9. Gartner Survey of 1,300 ClOs Shows IT Budgets to Increase by 2.5 Percent in 2005, Gartner Press. http://www.gartner.com/press releases/asset 117739 11.html (Accessed Feb 21 2007).

10. Gartner EXP Survey of More than I,400 CIOs Shows CIOS Must Create Leverage to Remain Relevant to the Business, Gartner Press. http://www.gartner.com/it/page.jsp?id=501189 (Accessed Feb 21 2007).

11. J. Ang and T. Ten, Management issues in data warehousing: Insights from the Housing and Development Board, Decision Support System. Volume 29, Number 1, pp.11-20, (2005).

12. T. Friedman, Gartner Says More Than 50 Percent of Data Warehouse Projects Will Hove Limited Acceptance or Will Be Failures Through 2007. http:/www.gartner.com/it/page.jsp?id=492112(Accessed Feb 21 2007).

13. D. Power, Decision Support Systems: Concepts and Resources for Managers (Westport, 2002). 
Towards a Critical Success Factor Framework for Implementing Business Intelligence Systems: A Delphi Study in Engineering Asset Management Organizations

14. P. Ponniah, Data Warehousing Fundamentals (Wiley-Interscience: New York, 2001).

15. J. Kulkarni and R. King, Business Intelligence Systems and Data Mining (SAS Institute Inc: 1997).

16. J. Han and M. Kamber, Data mining: Concepts and techniques (San Francisco: Morgan Kauffmann, 2001).

17. N.B. Duncan, Capturing Flexibility of Information Technology Infrastructure: A Study of Resource Characteristics and Their Measure, Journal of Management Information Systems. Volume 12, Number 2, pp.37-57, (1995).

18. W. Inmon, Building the Data warehouse (Wellesley, QED Technical Publishing Group: MA, 1992).

19. A. Sen and V. Jacob, Industrial-Strength Data Warehousing, Communications of the $A C M$. Volume 41, Number 9, pp.28-31, (1998).

20. J. Rockart, Chief Executives Define Their Own Data Needs, Harvard Business Review. Volume 57, Number 2, pp.81-93, (1979).

21. J. Rockart and J. Hoffman, System delivery: Evolving new strategies, Sloan Management Review. Volume 33, Number 4, pp.21-31, (1992).

22. H. Linstone and M. Turoff, The Delphi Method: Techniques and Applications (Reading, Addison-Wesley Publishing Company Inc: MA, 2002).

23. E. Ziglio, The Delphi Method and its Contribution to Decision-Making, in Gazing into the Oracle, The Delphi Method and Its Application to Social Policy and Public Health, (eds) M. Alder and E. Ziglio (London: Jessica Kingsley Publishers: 1996), pp.3-33.

24. D. Carson, A.Gilmore, C. Perry, and K. Gronhaug, Qualitative Marketing Research (Sage: London, 2001).

25. W. Delone and E. McLean, The DeLone and McLean model of information systems success: a ten-year update, Journal of Management Information Systems. Volume 19, Number 4, pp.9-30, (2003).

26. W. Delone and E. McLean, Information systems success: the quest for the dependent variable, Information System Research. Volume 3, Number 1, pp.60-95, (1992). 